\section{Sacred insects}

\section{Malcolm Coe}

Dung Beetle Ecology. Edited by Ilkka Hanski and Yves Cambefort. Princeton University Press: 1991. Pp. 481. \$60. $£ 43$.

THE apparently ceaseless energy with which the scarab beetle rolls its ball of dung has fascinated humans for at least 3,500 years. Ancient Egyptians saw in this activity an image of the Sun moving across the heavens, thus giving the humble insect its divine attributes. Oddly

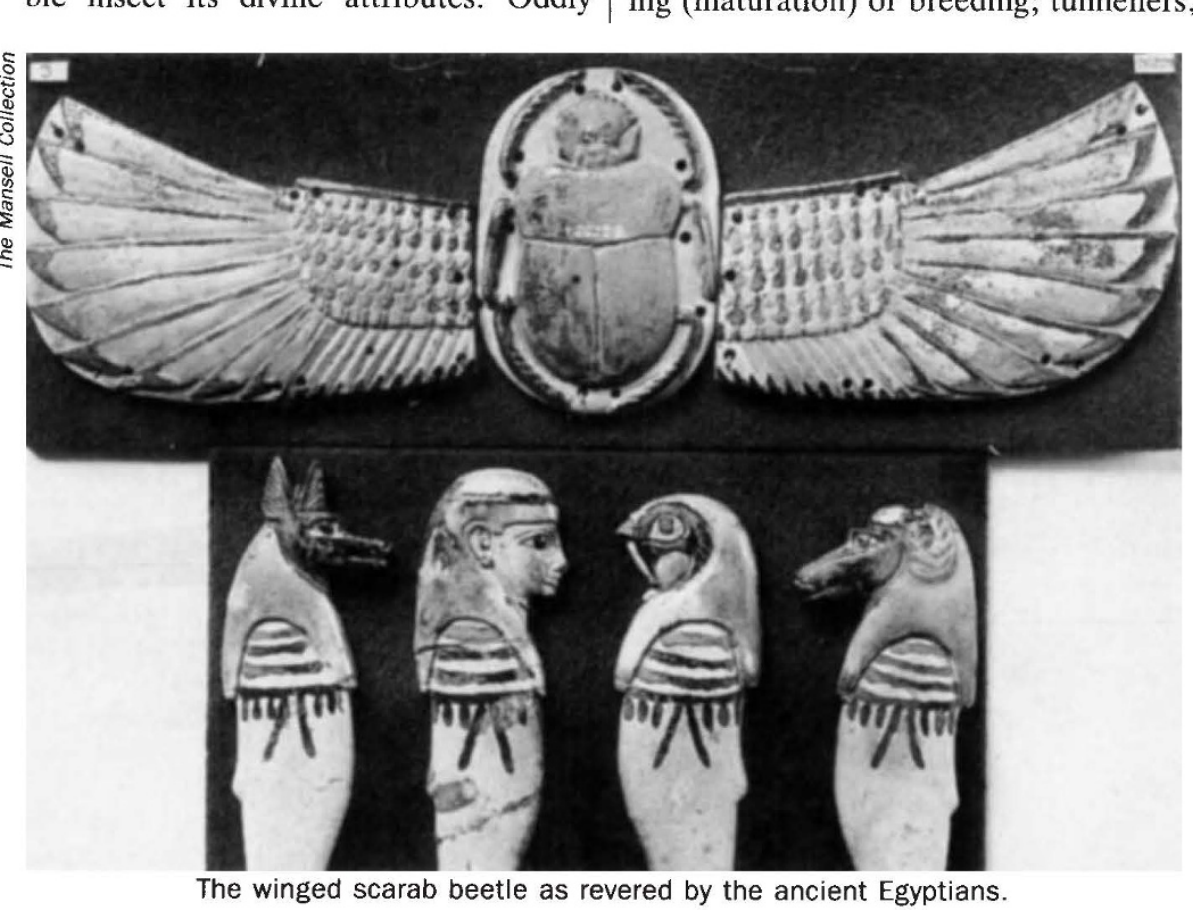

enough, in most of the many representations of the scarab, it is shown with the ball (or Sun) between its forefeet, while in reality the dung is rolled with the hindfeet. Cambefort has recently proposed that the attitudes of the ancient Egyptians to the scarab combined three important elements of these people's lives: the Sun, soil and cattle. In addition, signs of renewal may have been provided by the emergence of the beetle from its pupa in the brood ball, and the pyramids may have represented a stylized dung pat.

The editors of this volume have brought together excellent summaries of our current knowledge about these intriguing creatures' ecology and the evolution of their coprophagous lifestyle. It seems fairly clear that this lifestyle evolved from that of their saprophagous ancestors; even today there are many dung-beetle species and close relatives that feed on rotting vegetation rather than the digested plant litter of herbivorous mammals. The ancestors of these dung-feeding beetles first appear in the NATURE · VOL $355 \cdot 23$ JANUARY 1992 fossil record about 250 million years ago, which leads one to wonder whether the dung of large herbivorous dinosaurs led to the evolution of the first true dung beetles. It seems, though, that the main radiation of the modern species must have coincided with the radiation of herbivorous mammals much more recently. The shift from feeding on abundant but low-quality rotting vegetation to scarce and patchy high-quality resources was important in the evolution of the habits exhibited by today's dung beetles: rollers, which remove balls of dung from the site of deposition to bury them elsewhere for the purposes of feeding (maturation) or breeding; tunnellers,

which construct feeding or breeding burrows below the dung pile; and dwellers (generally small), which complete their feeding or breeding within the dung pile.

The great French entomologist Henri Fabre was the first to describe in detail the remarkable habits of dung beetles, especially those that show a high degree of brood care in raising their young within dung balls, which are often buried underground in specially constructed brood chambers.

Today, when many habitats and their accompanying herbivore faunas are being drastically altered or even exterminated by human activity, a detailed understanding of the ecological role and diversity of these diminutive recyclers of nutrients is vital. The book is directed primarily at those concerned with this ecology, but there is a great deal here for the general reader interested in "the natural history of the unmentionable". $\square$

Malcolm Coe is in the Department of Zoology, University of Oxford, South Parks Road, Oxford OX1 3PS, UK.

\section{Labours lost}

\section{Stuart Sutherland}

The Science of Love: Understanding Love and Its Effects on Mind and Body. By Anthony Walsh. Prometheus: 1991. Pp. 276. \$22.95, £14.50.

AN authoritative dictionary of psychology defined love as "a form of mental illness not yet recognised in the standard diagnostic manuals". Walsh will have none of such cynicism: indeed, he writes, "Only when we are loved and can give love in return do we feel whole ... .we yearn to be connected. Love beautifies our lives, it empowers our being, it ennobles us, it enriches us in every way, and it imbues our minds and hearts with a sense of the fullness of life." In short, Walsh is an enthusiast. $\mathrm{He}$ strives to demonstrate that love is a good thing and where possible to exhibit its physiological and psychological causes and consequences.

He argues that the absence of love, particularly in childhood, has disastrous effects. Certainly, Harlow's notorious infant monkeys, which were fed from an artificial metal mother, showed severe disabilities, but they made a considerable recovery later when allowed to consort with their peers. Although it is plausible to suppose that infants who are loved become happier adults than those who are not, there is precious little evidence to support this thesis. Walsh cites a few carefully selected findings that favour his case, but most studies, including some by John Bowlby, at one time the chief supporter of the importance of being loved as a child, suggest that deprived children usually make a complete emotional and intellectual recovery if they are moved to a better environment.

Walsh is on safer ground in claiming that bereavement and separation render people prone to all manner of illnesses and he sketches what is known of the harmful effects of unhappiness on the immune system. But as any hermit knows, there is a difference between not being loved and ceasing to be loved. Indeed, many psychiatrists believe that the effects of bereavement are greater in loveless marriages than in loving ones, an issue for which there is no good evidence. It is, however, known that any form of stress, such as that imposed by unemployment, moving house or even gaining promotion, can have the same effects on health as the loss of love.

In an attempt to justify the title of his book, Walsh strives to make connections between love and neurophysiology. In one of many wild speculations, he argues that "lack of love in infancy leads to 